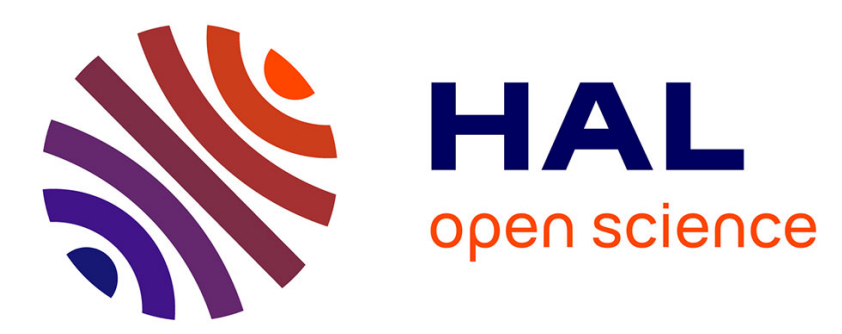

\title{
Elaboration of PIM feedstocks with 316L fine stainless steel powders for the processing of mico-components
}

Cedric Quinard, Jiu Peng Song, Thierry Barriere, Jean Gelin

\section{To cite this version:}

Cedric Quinard, Jiu Peng Song, Thierry Barriere, Jean Gelin. Elaboration of PIM feedstocks with 316L fine stainless steel powders for the processing of mico-components. Powder Technology, 2011, 208 (2), pp.383 - 389. 10.1016/j.powtec.2010.08.033 . hal-02300109

\section{HAL Id: hal-02300109 \\ https://hal.science/hal-02300109}

Submitted on 20 Nov 2019

HAL is a multi-disciplinary open access archive for the deposit and dissemination of scientific research documents, whether they are published or not. The documents may come from teaching and research institutions in France or abroad, or from public or private research centers.
L'archive ouverte pluridisciplinaire HAL, est destinée au dépôt et à la diffusion de documents scientifiques de niveau recherche, publiés ou non, émanant des établissements d'enseignement et de recherche français ou étrangers, des laboratoires publics ou privés. 


\title{
Elaboration of PIM feedstocks with 316L fine stainless steel powders for the processing of micro-components
}

\author{
C. Quinard, J. Song, T. Barriere *, J.C. Gelin \\ FEMTO-ST Institute, Applied Mechanics Department, UMR CNRS 6174, ENSMM Besançon, France
}

\begin{abstract}
The paper is concerned with the way to prepare feedstocks for powder injection moulding of fine stainless steel powders. The way to prepare adequate feedstocks is described, and injection moulding experiments are determined. The effects of powder volume loading, as well as mixing conditions are investigated and the results indicate that powder loading, injection moulding conditions and sintering kinetics largely influence the resulting shrinkage after sintering. Finally, the modelling and associated numerical simulations are used the help process design.
\end{abstract}

\section{Introduction}

Manufacturing of metallic micro-components has rapidly increased in the recent years due to the increasing demands from various applications, such as sensors, medical and energy devices [1]. Powder injection moulding (PIM) is now used to produce micro-parts since 15 years [2], but until now there is no commercial available feedstock based on powders with particles size smaller than $6 \mu \mathrm{m}[3]$. More and more investigations are currently focused on the manufacturing of micro-components with very fine stainless steel or other metallic powders [4]. On the other hand, the final mechanical properties and resulting microstructures of the sintered microcomponents made by micro-powder injection moulding ( $\mu \mathrm{PIM})$ is becoming another important issue as well as the dimensional accuracy.

$\mu$ PIM which combines the advantages of plastic micro-injection moulding and powder metallurgy is a competitive net-shape forming technology for manufacturing three dimensional micro-components in large batch [5-7]. The basic steps of $\mu$ PIM process include mixing, injection moulding, debinding and sintering. Mixing step aims to form the feedstock for injection moulding by mixing the metallic or ceramic powders with thermoplastic binders. Injection moulding stage leads to the green parts by filling the mould cavities with powder/binder mixture. The debinding step is used to remove the binder in the injection moulded parts without shape distortion by thermal, solvent or catalytic methods. In the subsequent sintering step, the debinded components are heated at a temperature just below the melting point of the main metallic constituent in order to obtain the required final

* Corresponding author. 24 rue de l'Epitaphe, 25000 Besançon, France. Tel.: + 33381 666075 ; fax: + 33381666700 .

E-mail address: thierry.barriere@univ-fcomte.fr (T. Barriere). density by bonding the powder particles together through solid state diffusion mechanisms.

The dimensional accuracy of the final components, as well as the physical and mechanical properties are mainly determined in the sintering stage. Sintering process for PIM parts significantly differs from the die-pressed sintering as it is only associated to solid state diffusion process, leading to large shrinkage (10-15\%) and fast sintering kinetics due to the large porosity after debinding and generally smaller particle sizes. Uneven shrinkage may be caused by gravity, friction between the component and the sintering support, small heterogeneity of the moulded parts due to segregation phenomena occurring during the mixing or injection moulding steps. Experimental and analyses of studies on the sintering processes have been carried out for more than 50 years. Models based on different physical approaches have been established for the modelling of sintering process based on simplifications of the complete physical processes [8]. Based on particle geometries for two or several particles, micro-structural based models focus on the analysis of neck growth between powder particles, pore geometries and shrinkage, according to different mass transport mechanisms [9]. The mesoscopic models, such as the Monte Carlo one, are based on a representative cell of the powder medium that is used to get the evolution of the microstructure [10]. The phenomenological models, based on continuum solid mechanics according to density variations mainly use finite element method accounting macroscopic sintering physical models to predict the dimensional changes of the sintered components during the sintering stage [11]. The previous works of the authors are related to the development of a sintering model and numerical simulations based on continuum mechanics to predict the shrinkages and distortions of the parts during and after sintering. The physical and material parameters used in the sintering models have been identified by experiments carried out in a dilatometer in real sintering conditions. 
In the proposed analysis, the feedstock for $\mu$ PIM has been developed on the basis of a fine 316L stainless steel powders, with particle size $d_{50}$ equal to $3.4 \mu \mathrm{m}$. The viscous behaviour of this feedstock during mixing, injection moulding, debinding and sintering steps has been investigated. The paper reports the shrinkage occurring during bending tests where the sintering process that has been carried out in a dilatometer under different sintering kinetics. Then finite element simulations have been used to predict the shrinkage of the sintered parts based on the phenomenological sintering model and physical parameters determined through the experiments in dilatometer.

\section{Experimental investigations}

\subsection{Material characterization}

316L stainless steel powders that are widely used in PIM, exhibits excellent mechanical and corrosion properties, as well as biocompatibility. The fine $316 \mathrm{~L}$ stainless steel powders that are used for $\mu$ PIM have generally a particle size $d_{50}$ equal to $3.4 \mu \mathrm{m}$. In the present analysis, the $316 \mathrm{~L}$ stainless steel powders (Osprey ${ }^{\circledR}$ Sandvik, UK) that are used exhibits a particle size distribution as follows: $d_{10}=1.8 \mu \mathrm{m}$, $d_{50}=3.4 \mu \mathrm{m}$ and $d_{90}=6.0 \mu \mathrm{m}$. The pycnometer density of the such powders is equal to $7.9 \mathrm{~g} \mathrm{~cm}^{-3}$. The chemical compositions for these stainless steel powders by weight are respectively $17.4 \% \mathrm{Cr}, 10.9 \% \mathrm{Ni}$, $2.5 \% \mathrm{Mo}, 1.2 \% \mathrm{Mn}, \mathrm{Si}, \mathrm{C}, \mathrm{P}$ and $\mathrm{S}<1 \%$. The SEM images show that the powders have spherical shapes that are well adapted for PIM due to the appropriate flowability (Fig. 1).

Several formulations based on wax binder systems as the primary binder, secondary binder and surfactant have been proposed for PIM feedstock [5]. The primary polymeric binders such as polypropylene (PP) and polyethylene (PE) are used to maintain the component shape after the injection moulding and debinding stages. The secondary binder such as paraffin wax (PW) is used to decrease the feedstock viscosity and consequently to increase the replication ability of the feedstock. The surfactants such as stearic acid (SA) or oleic acid (OA) are suitable to increase powder wetting. The characteristics and compositions of the binder systems which are suitable for thermal debinding are given in Table $1[12,13]$. Some of these formulations for the wax-based binder systems have been tested with powder loadings (powders volume fraction) equal to 60 in vol.\% [5]. Considering the facility to mix the feedstock and to get a mixture with excellent homogeneity [14], three binder formulations have been chosen for $\mu$ PIM in this study (Table 2).

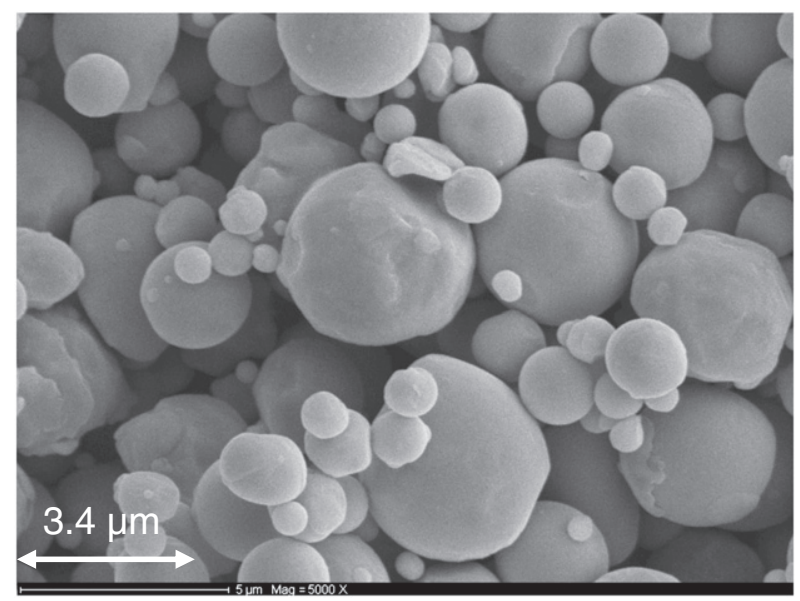

Fig. 1. Photography of $316 \mathrm{~L}$ stainless steel powders with particle size $d_{50}$ equal to $3.4 \mu \mathrm{m}$, used in the subsequent tests.
Table 1

Chemical composition and physical properties of the binder.

\begin{tabular}{lllll}
\hline Designation & Type & $\begin{array}{l}\text { Melting } \\
\text { temperature, }{ }^{\circ} \mathrm{C}\end{array}$ & $\begin{array}{l}\text { Density, } \\
\mathrm{g} \mathrm{cm}^{-3}\end{array}$ & $\begin{array}{l}\text { Decomposition, } \\
{ }^{\circ} \mathrm{C}\end{array}$ \\
\hline Polyethylene (LDPE) & Primary & 130 & 0.91 & 400 \\
Polypropylene (PP) & Primary & 140 & 0.90 & 400 \\
Paraffin wax (PW) & Secondary & 60 & 0.91 & 300 \\
Stearic acid (SA) & Surfactant & 70 & 0.94 & 395 \\
Oleic acid (OA) & Surfactant & 17 & 0.91 & 350 \\
\hline
\end{tabular}

\subsection{Experimental procedures}

The first experiment consists to choose the well appropriate binder formulation from the three ones related in Table 2 in order to get a well adapted feedstock for $\mu$ PIM with the fine 316L stainless steel powders. A torque rheometer with two blade screws (Plastograph ${ }^{\circledR}$, Brabender, Germany) has been used to mix the powder and binder. The powder loading was chosen as $60 \mathrm{vol}$. \%. The mixing temperature was $160^{\circ} \mathrm{C}$. The screw rotated at $30 \mathrm{rpm}$ during $30 \mathrm{~min}$. Finally, the feedstock has been granulated in small pellets for easy injection moulding.

After the determination of the appropriate binder formulation, the critical powder loading was investigated using a torque rheometer. The method consists to progressively increase the solid volume loading during the test, with a fixed binder volume [15]. The powder loading varies from 50 to 66 vol.\% with increasing step equal to 2 vol.\% for each level by adding the powders content. The principle of this method consists to incrementally add powders content up to a maximum value corresponding to the significant increasing of the mixing torque vs. powder loading. The test presents the advantage to provide the way determine the critical powder loading by using just one testing cycle. But the entire heating cycle take around $225 \mathrm{~min}$ (test including 15 powder loading levels), and the intensive shearing can lead to the decomposition of the stearic acid. Consequently, a mixing temperature was chosen as low as possible $\left(160^{\circ} \mathrm{C}\right)$ to reduce this effect. Formulation 2, based on PP, PW and SA, was used to determine the critical powder volume loading.

A two-plate mould with micro-cavities corresponding to tensile and bending test specimens has been designed (Fig. 2a). The cross section area for the cavity gates (type 3 and 4 ) is $0.5 \mathrm{~mm}^{2}$. These cavities have been obtained by electrical discharge machining (EDM) and high speed machining (HSM). The developed feedstock used for injection moulding consists of fine 316L stainless steel powders with particle size $d_{50}$ equal to $3.4 \mu \mathrm{m}$ and binder system corresponding to the formulation 2 related in Table 2. The powder loading of the feedstock corresponds to $60 \mathrm{vol} \%$. Micro-components has been injected in using a hydraulic injection moulding equipment (Arburg ${ }^{\circledR}$ Allrounder 220S). A special screw for the MIM feedstock injection, with a diameter equal to $15 \mathrm{~mm}$ and a length equal to $600 \mathrm{~mm}$, has been used for the different injection moulding tests. The process parameters for the injection moulding stage are the following: injection temperature equal to $190^{\circ} \mathrm{C}$, mould temperature equal to $65{ }^{\circ} \mathrm{C}$, maximum injection pressure equal to $100 \mathrm{MPa}$, flow rate equal to $20 \mathrm{~cm}^{3} \mathrm{~s}^{-1}$ associated to a screw speed equal to $10 \mathrm{~m} \mathrm{~min}^{-1}$. The total injected volume corresponds to $2 \mathrm{~cm}^{3}$. The microstructures of

Table 2

Polymers volume fraction used for the feedstocks.

\begin{tabular}{lccccl}
\hline Formulation (vol.\%). & PP, \% & PE, \% & PW, \% & SA, \% & OA, \% \\
\hline 1 & 0 & 40 & 0 & 60 & 0 \\
2 & 40 & 0 & 55 & 5 & 0 \\
3 & 94 & 0 & 0 & 0 & 6 \\
\hline
\end{tabular}


a)

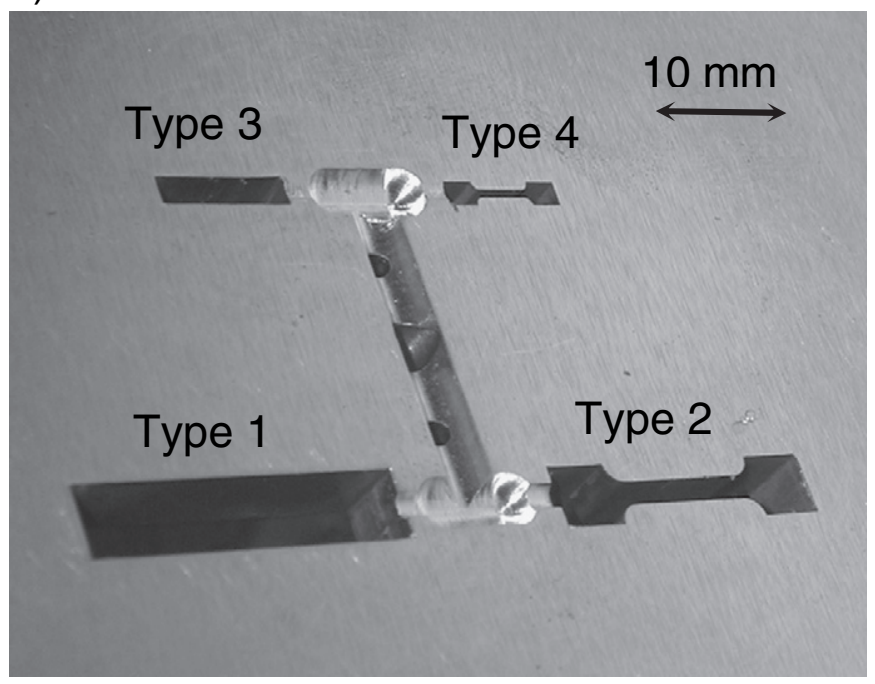

b)

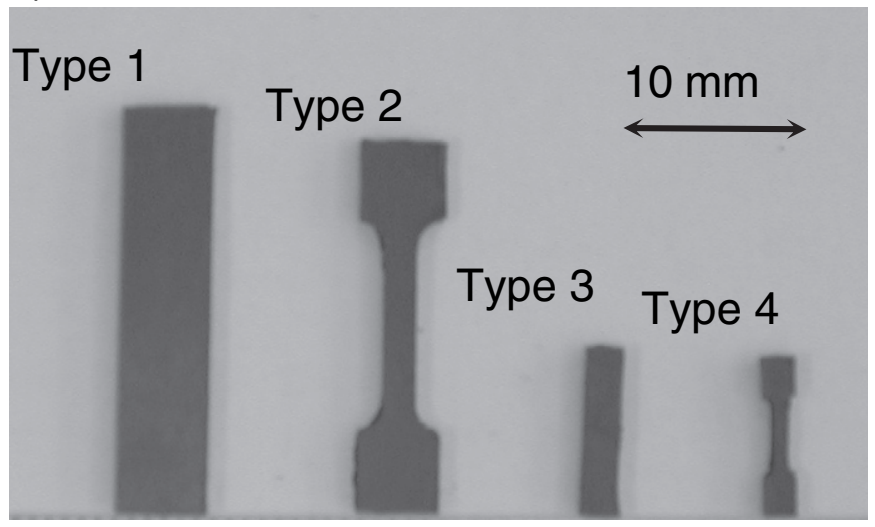

Fig. 2. (a) Die cavity comprising two bending test specimens (type 1 and 3) and two tensile test specimens (type 2 and 4 ) with a thickness equal to $1 \mathrm{~mm}$; (b) microcomponents after injection moulding based on $316 \mathrm{~L}$ stainless steel powders ( $d_{50}$ equal to $3.4 \mu \mathrm{m})$.

the mixed and injected components have been studied by SEM observation. The stainless steel powders exhibited an appropriate homogeneity where the stainless steel powders are uniformly distributed within the binder, see Fig. 3.

The debinding is performed to eliminate the binder after injection moulding. After debinding, only the primary binder remains with the powders that ensure a minimum strength of the component [16]. The thermal debinding was selected associated to its simplicity, safety and environment protection. The debinding was realized in a thermal debinding oven at $220^{\circ} \mathrm{C}$ in argon atmosphere. The debinding temperature cycle consist in two stages: (1) heating from ambient temperature to $130{ }^{\circ} \mathrm{C}$ in $2 \mathrm{~h}$ and (2) heating from $130{ }^{\circ} \mathrm{C}$ to $220^{\circ} \mathrm{C}$ in $24 \mathrm{~h}$.

The sintering was carried in a high temperature furnace under vacuum conditions. The heating rate for the sintering cycles varies from 5 to $20^{\circ} \mathrm{C}$ $\min ^{-1}$. Two holding stages have been used: (1) $600^{\circ} \mathrm{C}$ during 30 min and (2) $1360{ }^{\circ} \mathrm{C}$ during $120 \mathrm{~min}$. The furnace vacuum was $10^{-3} \mathrm{mbar}$ and alumina plates were used for sintering supports. The sintered parts were cooled in furnace from sintering temperature to the ambient one with a cooling rate corresponding to $10{ }^{\circ} \mathrm{C} \mathrm{min}^{-1}$.

\subsection{Results}

The mixing torque curves for the feedstock with a fixed powder loading equal to 60 vol.\% corresponding to the 3 binder formulations

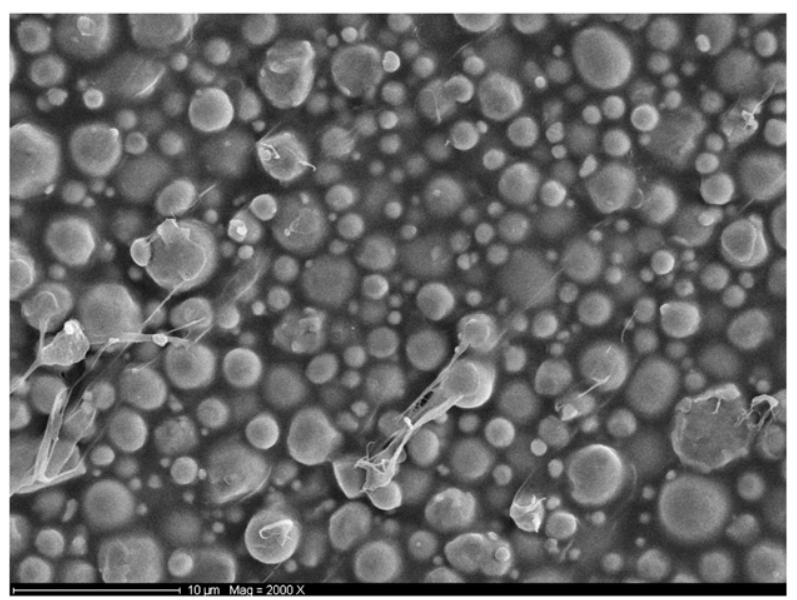

Fig. 3. SEM pictures of feedstock after injection stage, corresponding to the formulation 2 (powder loading equal to $60 \%$ in vol., $316 \mathrm{~L}$ stainless steel powders, $d_{50}$ equal to $3.4 \mu \mathrm{m}$ ) (mixing temperature: $160^{\circ} \mathrm{C}$, mixing rotation speed: $30 \mathrm{rpm}$ and mixing time: 30 min.).

are related in Table 2 and are plotted in Fig. 4a. The feedstock corresponding to formulation 2 exhibits the lower torque that corresponds to the lower viscosity. The final mixing torque corresponding to formulation 2 is about $0.3 \mathrm{~N} . \mathrm{m}$ compared with 16 N.m and 5 N.m for the formulations 1 and 3, in addition, the shear

a)

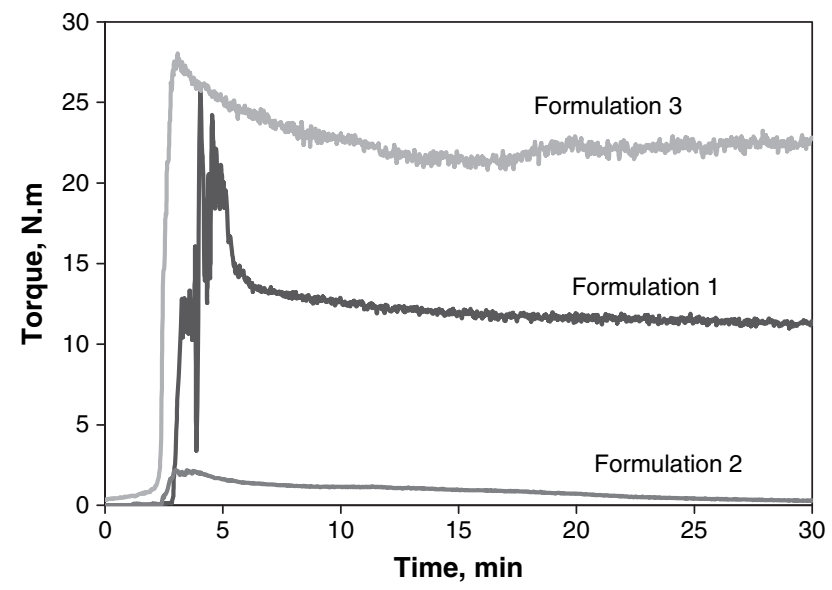

b)

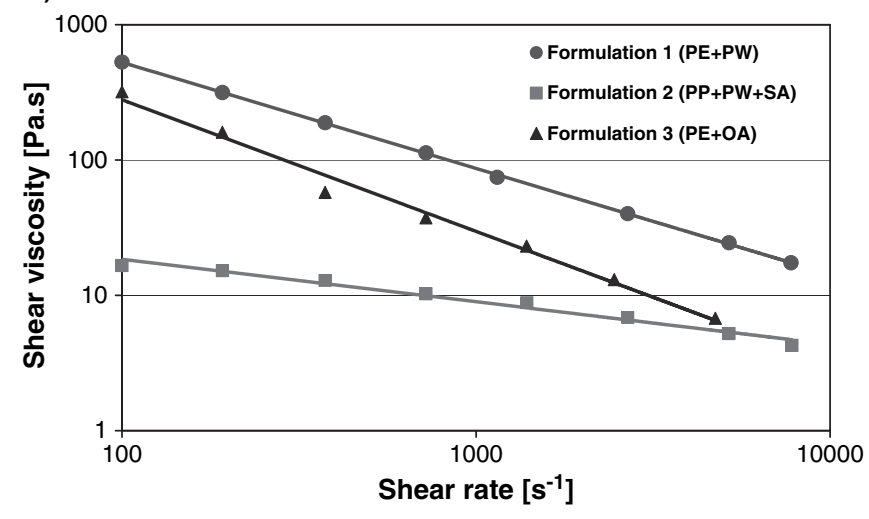

Fig. 4. a) Mixing torque curves vs. time corresponding to three different feedstock formulations (powder loading equal to $60 \mathrm{vol} . \%$ ); b) Shear viscosity vs. shear rate for the three different feedstocks (powder loading equal $60 \mathrm{v} / \mathrm{o}$, measured with capillary rheometer at $160{ }^{\circ} \mathrm{C}$, capillary die diameter equal $1 \mathrm{~mm}$ ) corresponding to the three different formulations. 
viscosities of the three formulations are related in Fig. 4b, formulation $2(\mathrm{PP}+\mathrm{PW}+\mathrm{SA})$ exhibits the smallest shear viscosity among them. So the binder associated to formulation 2 is more appropriate than formulation 1 and 3 for mixing with the fine 316L stainless steel powders to elaborate the $\mu$ PIM feedstock with a proper flowability.

The formulation 2 corresponding to a binder based on PP, PW and $\mathrm{SA}$, has been used for the determination of the critical powder loading. In Fig. 5, one can clearly observe that there are three obvious stages of the mixing torque corresponding to the increasing of powder content loading. In the first stage, the mixing torque keeps at a low value and increases slightly, as the powder loading ranges from 50 to $60 \mathrm{vol} . \%$. In the second stage, the powder is added until the powder loading reaches 66 in vol.\%, and the third stage corresponds to the abrupt increase of the mixing torque. The resulting feedstock cannot be used for injection moulding due to high viscosity. So the critical powder loading for the related feedstock system is in the range from 64 to 66 vol.\%. Generally the optimal powder loading should be about 2 to 5 vol.\% lower than the critical one [5]. In this study, the powder loading used for the injection moulding tests is chosen as $60 \mathrm{vol} . \%$.

The micro-components have been moulded without defects such as jetting and dead zone, as shown in Fig. $2 \mathrm{~b}$. The thickness of the parts is $1 \mathrm{~mm}$. The micro parts corresponding to bending test specimens and cylindrical ones are used for the sintering experiments in order to determine the material parameters related to the sintering model that will be described in the following section. The debinded parts are homothetic to the moulded ones, but a small shrinkage around $1 \%$ for the large tensile test specimen is observed (Fig. 6). The sintered parts are carefully measured in order to determine the shrinkage. The average shrinkage with reference to the mould dimensions are between $11.5 \%$ and $15.0 \%$, depending on the heating rates used in the thermal cycles during sintering. In a first approximation and considering an isotropic shrinkage, the average relative density $d$ of the sintered parts can be calculated from the average shrinkage using the following expression [17]:

$d=\Phi /(1-\delta)^{3}$

where $\Phi$ is the powder loading and $\delta$ is the shrinkage after sintering. The relative density increases generally as the heating rate increases during sintering, see Fig. 7. The relative density varies from $92 \%$ to $98 \%$ vs. heating rates. A higher final relative density corresponding to $98 \%$ has been obtained by using a heating rate equal to $10^{\circ} \mathrm{C} \mathrm{min}^{-1}$.

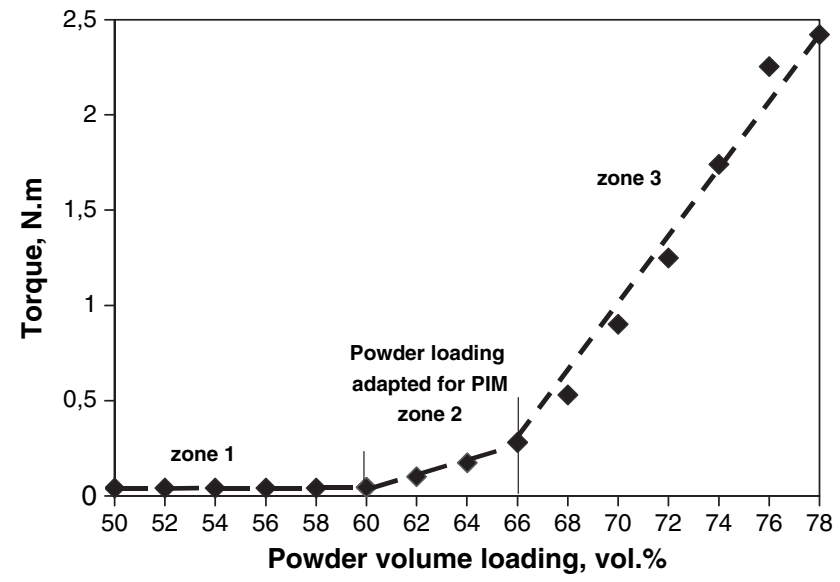

Fig. 5. Mixing torque vs. powder volume loading associated with formulation 2 (55\% $\mathrm{PP}+40 \% \mathrm{PW}+5 \% \mathrm{SA}$ ) and $316 \mathrm{~L}$ stainless steel powders with particle size $d_{50}$ equal to $3.4 \mu \mathrm{m}$.

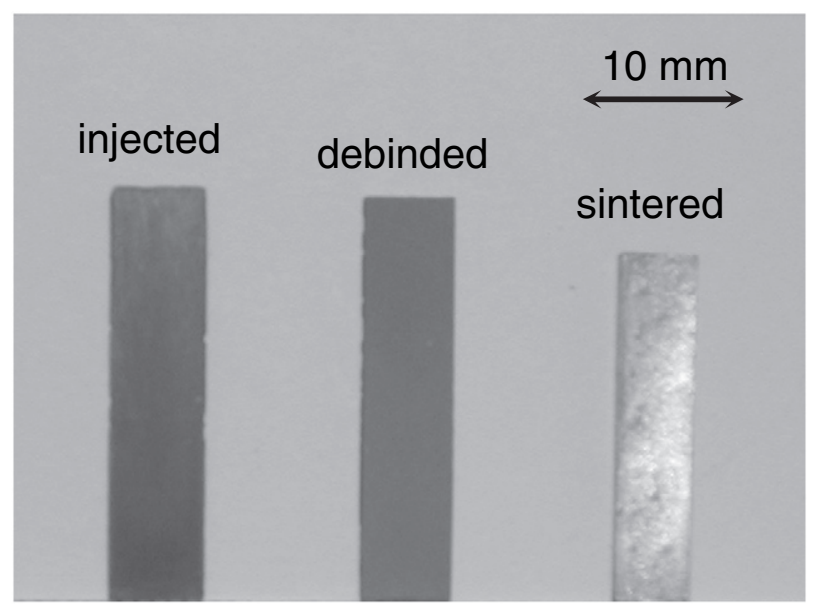

Fig. 6. Injected, debinded and sintered specimens in $316 \mathrm{~L}$ stainless steel powders $\left(d_{50}\right.$ equal to $3.4 \mu \mathrm{m}$ ), with heating rate equal to $10^{\circ} \mathrm{C} \mathrm{min}^{-1}$ and then constant temperature equal to $1360{ }^{\circ} \mathrm{C}$ during $120 \mathrm{~min}$.

\section{Physical modelling and numerical simulation of the sintering stage}

\subsection{Continuum sintering model}

The macroscopic shrinkage and distortion of the resulting parts during and after sintering can be analyzed in using continuum mechanics conservation laws coupled with a thermo-elasto-viscoplastic constitutive laws [11]. The strain rate consists in three parts: elastic strain rate associated to the elastic deformations $\dot{\varepsilon}^{e}$, thermal strain rate associated to thermal deformations $\dot{\varepsilon}^{\text {th }}$, viscoplastic strain rate associated to viscoplastic deformations $\dot{\varepsilon}^{v p}$, and can be written:

$\dot{\varepsilon}=\dot{\varepsilon}^{e}+\dot{\varepsilon}^{t h}+\dot{\varepsilon}^{v p}$

The stress rate $\dot{\sigma}$ can be expressed vs. $\dot{\varepsilon}^{e}, \dot{\varepsilon}^{\text {th }}$ and $\dot{\varepsilon}^{v p}$ as following:

$\dot{\sigma}=D^{e} \dot{\varepsilon}^{e}=D^{e}\left(\dot{\varepsilon}-\dot{\varepsilon}^{t h}-\dot{\varepsilon}^{v p}\right)$

where $D^{e}$ is the isotropic elasticity tensor. The thermal strain rate $\dot{\varepsilon}^{\text {th }}$ is limited to thermal expansion as expressed in Eq. (4):

$\dot{\varepsilon}^{\text {th }}=\alpha \Delta \dot{T} I_{d}$

where $\alpha$ is the coefficient of thermal expansion, $\Delta T$ is the temperature increment and $I_{d}$ is the second order identity tensor. The viscoplastic

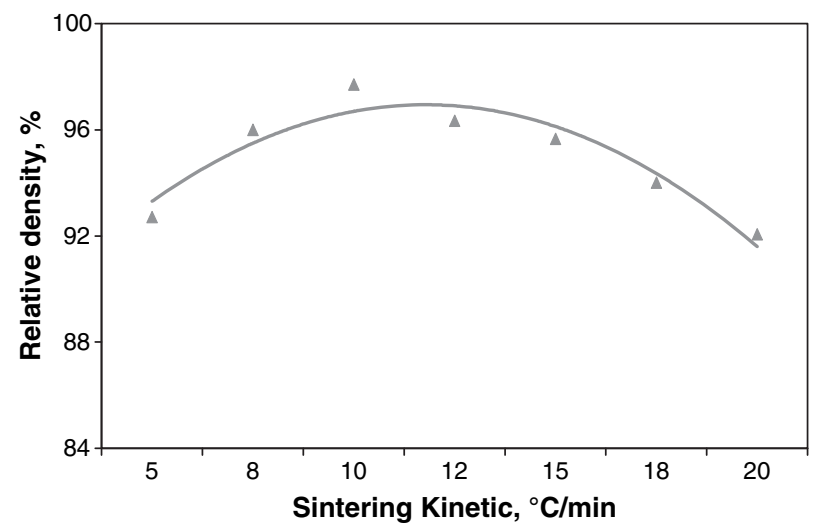

Fig. 7. Relative density vs. heating rate for the components in $316 \mathrm{~L}$ stainless steel powders with particle size $d_{50}$ equal to $3.4 \mu \mathrm{m}$. 
strain rate $\dot{\varepsilon}^{v p}$, corresponding to the sintering mechanisms by solid state diffusion, is determined through the expression below [11]:

$\dot{\varepsilon}^{v p}=\frac{\operatorname{dev} \sigma}{2 G}+\frac{\sigma_{m}-\sigma_{s}}{3 K} I_{d}$

where $\operatorname{dev} \sigma$ is the deviatoric stress tensor, $G$ is the shear viscosity modulus, $\sigma_{m}=\operatorname{tr}(\sigma) / 3$ mean stress, $\sigma_{s}$ is the sintering stress. $K$ is the bulk viscosity modulus and $I_{d}$ is the second order identity tensor. The shear and bulk viscosity modules are expressed through Eqs. (6) and (7) issue from [18]:

$G=\frac{\eta_{z}}{2\left(1+v_{p}\right)}$

$K=\frac{\eta_{z}}{3\left(1-2 v_{p}\right)}$

where $\eta_{z}$ is the uniaxial viscosity and $\nu_{p}$ is the Poisson's ratio of the porous material. These coefficients can be determined through experiments. The uniaxial viscosity $\eta_{z}^{e}$ could be measured in using bending tests during sintering with the following expression [19]:

$\eta_{z}^{e}=1 \dot{\delta} \frac{F L_{s}^{3}}{4 b h^{3}}$

where $\dot{\delta}$ is the measured deflection rate of the bending specimen, $L_{s}$ is the span length of the bending tests, $h$ and $b$ are respectively the thickness and the width of specimen before deformation and $F$ is the axial load applied perpendicularly to the specimen (Fig. 8). The Poisson's ratio of the sintering material can be expressed through the following expression [18]:

$v_{p} \approx \frac{1}{2} \sqrt{\frac{d}{3-2 d}}$

where $d$ is the relative density that could increase from 0.6 to 1 . The sintering stress is a function of relative density and particles size [20] expressed as:

$\sigma_{\mathrm{s}}=B d^{C}$

where $B$ and $C$ are the physical parameters to be determined from the experiments in dilatometer.

\subsection{Determination of the constitutive parameters}

The identification of the physical parameters entering in the constitutive and phenomenological relationship as previously mentioned is realized through an inverse method based on free or loaded tests and bending tests under fixed load during sintering in dilatometer [17]. The dilatometric measurements have been carried out at high temperature in an horizontal dilatometer (Netzsch ${ }^{\circledR}$ DIL 402C). This equipment proceeds under primary vacuum and a normal load equal to $15 \mathrm{cN}$ is applied on the specimen. The span distance for

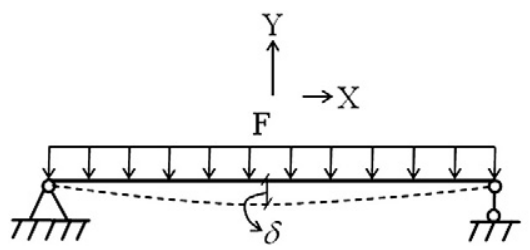

Cross section of beam

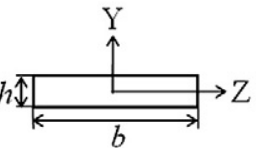

Fig. 8. Description of simply supported beam model for beam-bending tests the bending tests is $10 \mathrm{~mm}$. The axial deflection and shrinkage measurements were conducted with different heating rates equal to 5,10 and $15^{\circ} \mathrm{C} \mathrm{min}^{-1}$. The temperature of these tests are in the range from $25^{\circ} \mathrm{C}$ to $1360{ }^{\circ} \mathrm{C}$. The holding times at $1360{ }^{\circ} \mathrm{C}$ are $120 \mathrm{~min}$. The results are related in Figs. 9 and 10.

In the sintering model used in the analysis, uniaxial viscosity $\eta_{p}$ and sintering stress $\sigma_{s}$ are the parameters that should be identified. The bending and shrinkage tests in dilatometer during sintering are used to determine both parameters respectively [17]. The obtained uniaxial viscosity for the heating and holding periods during sintering with different heating rates are related in Fig. 11. An inverse identification method is used to determine the sintering stress. This method is based on the minimization of the following objective function:

$\left\{\begin{array}{l}\min G(x) \\ G(x)=\sum_{i=1}^{n}\left|\lambda^{e}\left(T_{i}, x\right)-\lambda^{m}\left(T_{i}, x\right)\right|^{2} \\ x=[B, C]\end{array}\right.$

where $G(x)$ is the objective function, $\lambda^{e}$ is the shrinkage issued from dilatometric tests, $\lambda^{m}$ is the shrinkage calculated with the sintering model, $n$ corresponds to the number of the points on the shrinkage curves recorded by the dilatometer, $B$ and $C$ are the physical parameters to be identified. Based on the determined uniaxial viscosity and shrinkage tests in dilatometer, an optimization algorithm [21] is used to solve the minimisation problem (11). The optimization is divided into two stages by a critical relative density

a)

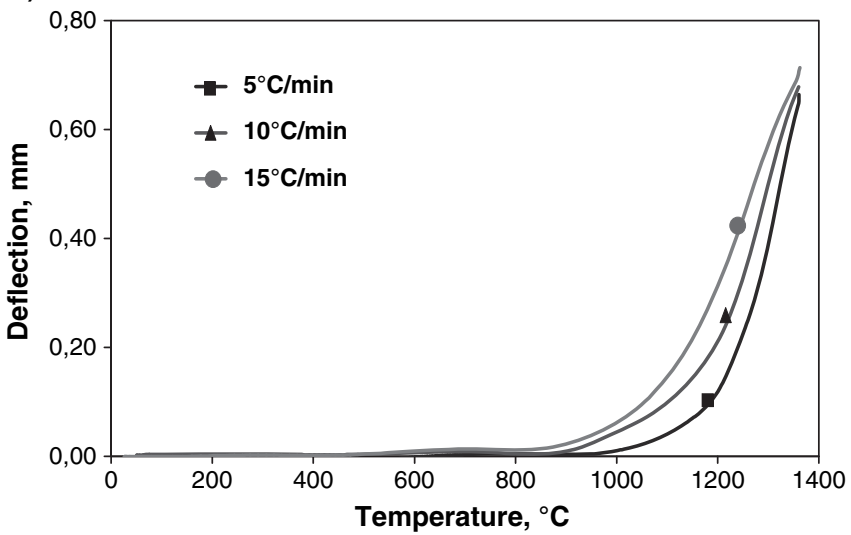

b)

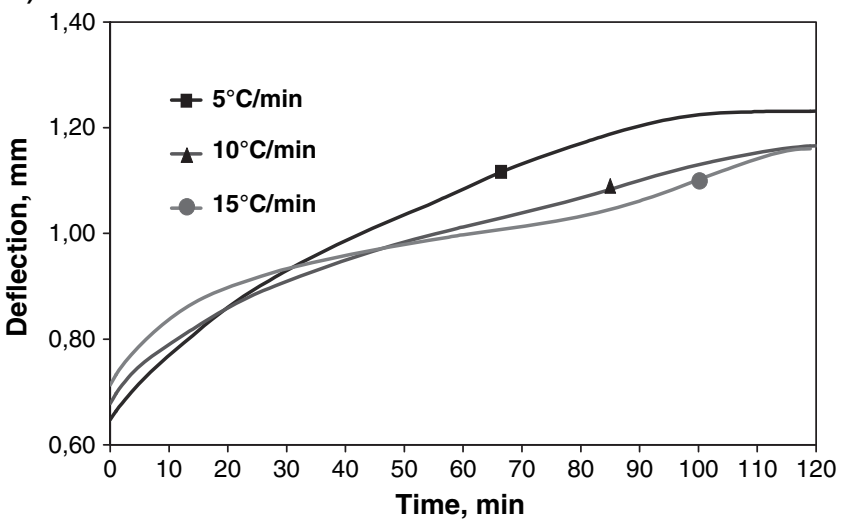

Fig. 9. Variation of axial deflection during (a) heating and (b) holding stages for the components made with $316 \mathrm{~L}$ stainless steel powders ( $d_{50}$ equal to $3.4 \mu \mathrm{m}$ ). 
a)

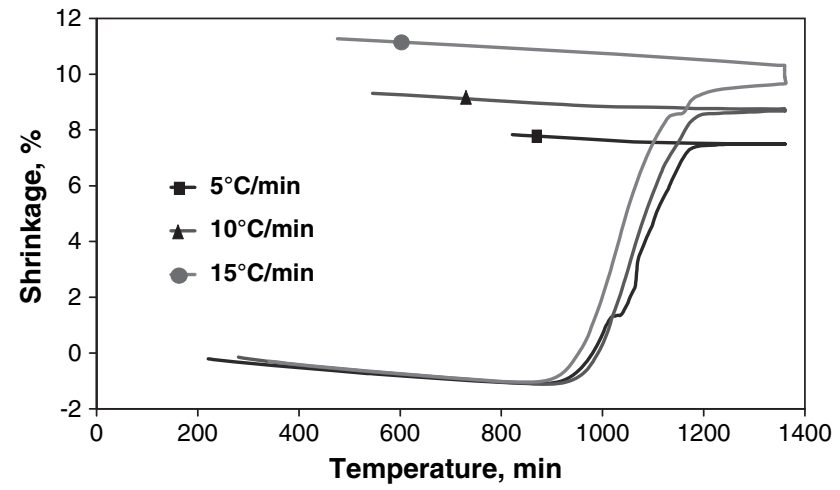

b)

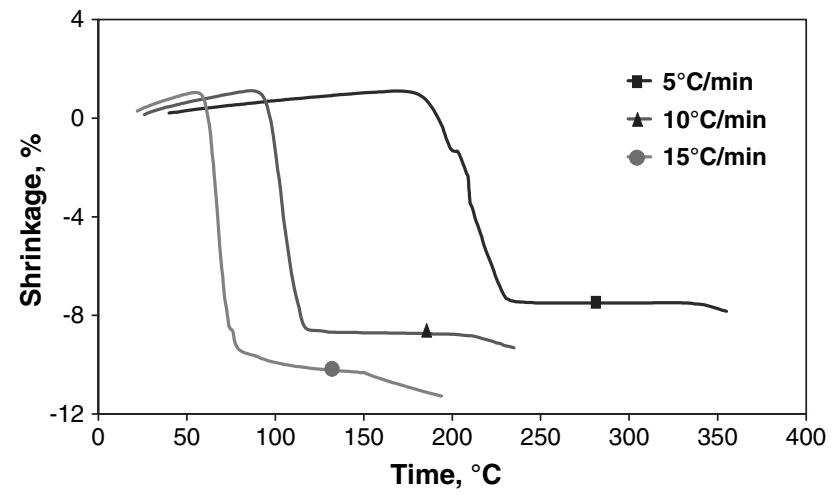

Fig. 10. Shrinkage variation vs. temperature and time during the sintering stages for the components in 316L stainless steel ( $d_{50}$ equal to $\left.3.4 \mu \mathrm{m}\right)$.

80\%. The determined sintering stress $\sigma_{s}$ expressed as a function of relative density (Eq. (10)) is shown in Fig. 12.

\subsection{Numerical simulations of the sintering stage}

The numerical simulations based on the above sintering model have been implemented in the Abaqus ${ }^{\circledR}$ finite element software, through the user subroutine UMAT. The initial geometries of components used for the simulation consist of a bending test specimen with a length equal to $25 \mathrm{~mm}$, a width equal to $5.5 \mathrm{~mm}$ and a thickness equal to $1 \mathrm{~mm}$, and a tensile test specimen with a length equal to $10 \mathrm{~mm}$, a section width at central position equal to $2 \mathrm{~mm}$ and a thickness equal to $0.9 \mathrm{~mm}$. The powder loading of the green parts is 60 vol.\%. The sintering cycles, used to perform the simulations correspond to heating rates equal to 5,10 and $15^{\circ} \mathrm{C} \mathrm{min}{ }^{-1}$ and holding temperature equal to $1360^{\circ} \mathrm{C}$ during $120 \mathrm{~min}$. The sintering simulations have been realized considering an alumina support plate, with a friction coefficient equal to 0.5 , the gravity effect is also considered [17].

The simulations of the sintering stage have been carried out for components corresponding to the 316 Ltainless steel powders with $d_{50}$ particle size equal to $3.4 \mu \mathrm{m}$. The shrinkage of the specimens after sintering stage, corresponding to a heating rate equal to $5{ }^{\circ} \mathrm{C} \mathrm{min}-1$ are obtained by simulation, are shown in Fig. 13a and b. The results of all the simulations indicate that the shrinkage as well as the relative density increase with the heating rate (Table 3). The maximum of the isotropic shrinkage and final relative density have been obtained for a thermal kinetics corresponding to $15^{\circ} \mathrm{C} \mathrm{min}^{-1}$.

A comparison between simulations and experiments considering shrinkage and relative density is related in Table 3. The values of relative density are lower than the experimental ones. The maximum discrepancy is less than $10 \%$. Nevertheless, the difference between a)

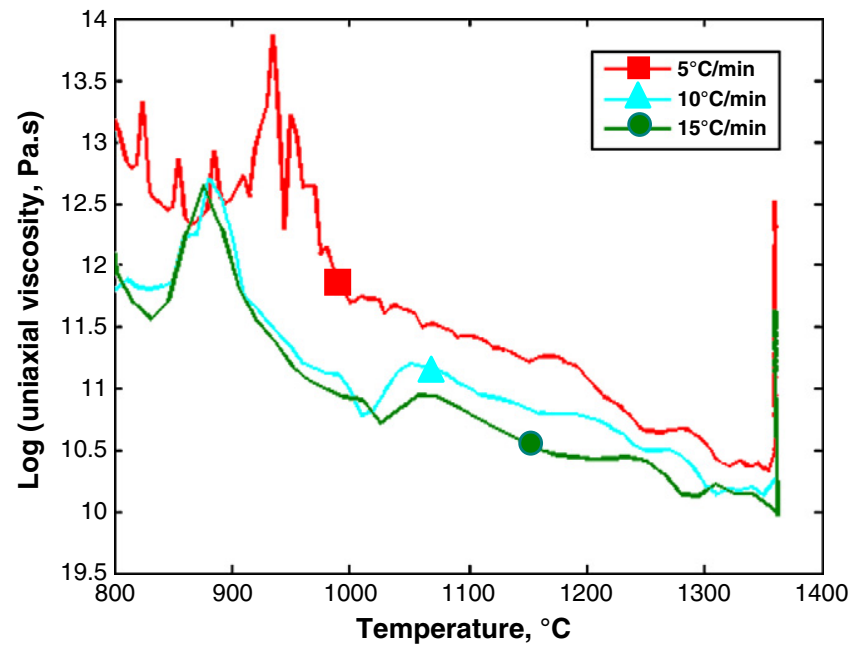

b)

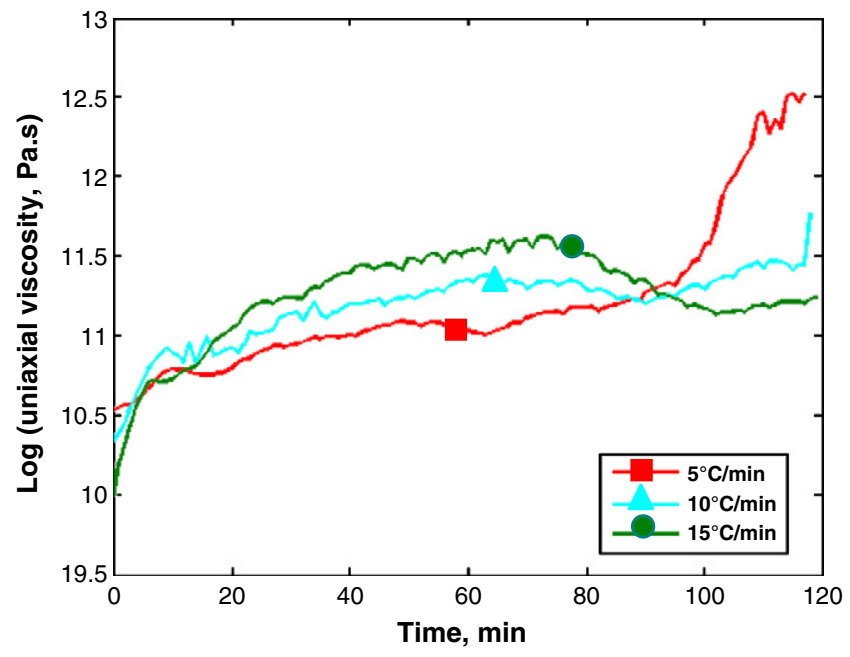

Fig. 11. Variation of uniaxial viscosity during heating (a) and holding (b) stages for $316 \mathrm{~L}$ stainless steel components ( $d_{50}$ equal to $3.4 \mu \mathrm{m}$ ).

simulations and experiments can be reduced by considering heterogeneous powders volume fractions after injection moulding stage or near proper friction coefficient carefully measured from experiments.

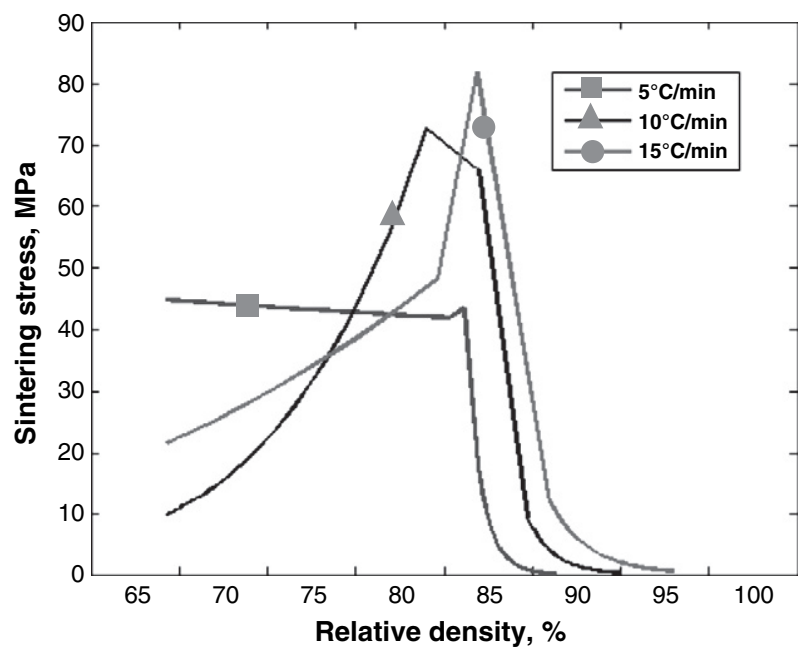

Fig. 12. Evolution of sintering stress during heating and holding stages for 316L stainless steel components, with particle size $d_{50}$ equal to $3.4 \mu \mathrm{m}$. 
a)

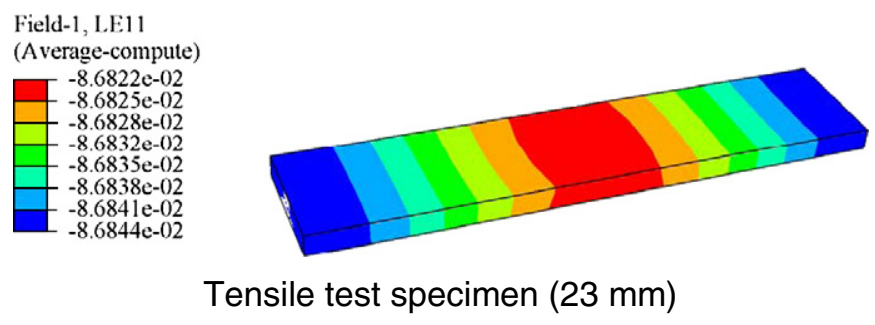

b)

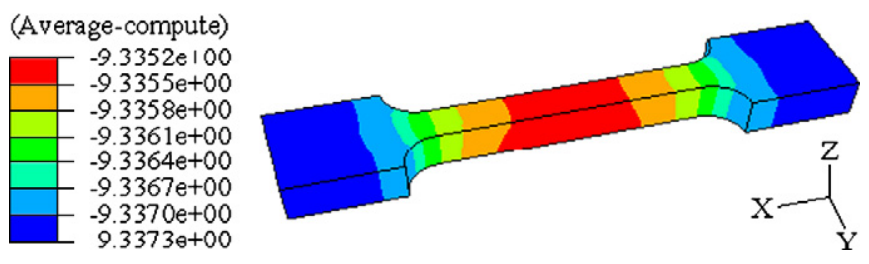

Bending test specimen $(10 \mathrm{~mm})$

Fig. 13. Shrinkage of the specimens after sintering stage corresponding to a heating rate equal to $5{ }^{\circ} \mathrm{C} \min ^{-1}$ : a) beam bending specimen (initial length: $23 \mathrm{~mm}$ ); b) tensile specimen (initial length: $10 \mathrm{~mm}$ ).

Table 3

Comparison of relative density obtained from experiments and simulation at different temperature rates.

\begin{tabular}{llll}
\hline $\begin{array}{l}\text { Kinetic } \\
\left({ }^{\circ} \mathrm{C} / \mathrm{min}\right)\end{array}$ & Density obtained & $\begin{array}{l}\text { Discrepancy } \\
(\%)\end{array}$ \\
\cline { 2 - 3 } & From simulation (\%) & From experiments (\%) & 7.00 \\
\hline 5 & 86.22 & 92.70 & 9.24 \\
10 & 89.85 & 99.00 & 2.96 \\
15 & 92.87 & 95.70 & \\
\hline
\end{tabular}

\section{Conclusions}

This study demonstrates the possibility to realize metallic microcomponents by micro-powder injection moulding ( $\mu \mathrm{PIM})$. It has been shown that the fine metallic powders can be properly mixed with polymers to make suitable feedstocks for micro-injection moulding. The micro-components exhibit very small shrinkage after injection and debinding. However, the components exhibit inhomogeneous shrinkage after sintering ranging from $11.5 \%$ to $15 \%$, depending on the part size and sintering kinetics. The continuum sintering model based on thermo-elasto-viscoplastic constitutive law could provide component shrinkage, which is helpful to determine the die cavity geometry that has to be used in injection moulding. The parameters used in the sintering model could be obtained from bending and shrinkage tests carried out in a dilatometer. In order to improve the accuracy of the simulation results, the powder inhomogeneity in the moulded parts has to be accounted as well as friction coefficient between the parts and sintering supports that should be properly defined.

\section{References}

[1] L. Federzoni, P. Revirand, Micro-channelled heat exchanger manufactured by ceramic injection moulding and co-firing, Powder Inject. Mould. Int. 2 (2008) 69-71.

[2] A. Rota, T.V. Duong, T. Hartwig, Wear resistant tools for reproduction technologies produced by micro powder metallurgy, Microsyst. Technol. 7 (2002) 225.

[3] T. Barriere, J.C. Gelin and B. Liu, Experimental and numerical investigations on the properties and quality of parts produced by MIM, Powder Metallurgy, Ed. by Maney Publishing, vol. 44, 3, 2001, pp. 228-234.

[4] Q. Wang, H. Yin, X. Qu, J.L. Johnson, Effects of Mold Dimensions on Rheological of Feedstock in Micro Powder Injection Molding, Powder Technol. 193 (1) (July 10 2009) 15-19.

[5] R.M. German, Status of PIM Research and Development, PIM 2007, Int. Conference on Injection Moulding of Metals and Ceramics, Ed. by M.P.I.F, 2007.

[6] V. Piotter, M. Beck, K. Plewa, H.-J. Ritzhaupt-Kleissl, A. Ruh, J. Hausselt, Micro PIM moves into the zone of industrial possibility, Metal Powder Rep. 64 (9) (October 2009) 35-37.

[7] G. Kukla, Micro injection moulding, Int. J. Form. Process. 4 (3-4) (2001) 253-267.

[8] R.M. German, Computer modelling of sintering processes, Int. J. Powder Metallurgy 38 (2) (2002) 48-66.

[9] R.L. Coble, Sintering crystalline solids. I. Intermediate and final state diffusion models, J. Appl. Phys. 32 (5) (1961) 787-792

[10] M. Braginsky, V. Tikare, E.A. Olevsky, Numerical simulation of solid state sintering, Int. J. Solids Struct. 42 (2005) 621-636.

[11] E.A. Olevsky, Theory of sintering: from discrete to continuum, Mater. Sci. Eng. R 23 (1998) 41-100.

[12] L. Liu, N.H. Loh, B.Y. Tay, S.B. Tor, Y. Murakoshi, R. Maeda, Mixing and characterisation of 316L stainless steel feedstock for micro powder injection molding, Mater. Charact. 54 (2005) 230-238.

[13] B.Y. Tay, N.H. Loh, S.B. Tor, F.L. Ng, G. Fu, X.H. Lu, Characterisation of micro gears produced by micro powder injection moulding, Powder Technol. 188 (3) (2009) 179-182.

[14] C. Quinard, T. Barriere, J.C. Gelin, Development and properties identification of 316L stainless steel feedstock for PIM and $\mu$ PIM, Powder Technol. 190 (1-2) (2009) 123-128.

[15] F.M. Barreiros, M.T. Viera, J.M. Castanho, Role of Nanostructured Layers on Powders during Sintering of Low Carbon Austenitic Stainless Steel, Euro PM2008, vol. 2, 2008, pp. 311-316.

[16] R.M. German, A. Bose, Wick debinding distortion of injection molded powder compacts, Int. J. Powder Metall. 26 (1990) 217-230.

[17] J. Song, T. Barriere, B. Liu, J.C. Gelin and M. Gerard, Experimental and numerical analysis on sintering behaviours of injection moulded components in 316L stainless steel powder, Powder Metall. in press, doi:10.1179/003258908X334212.

[18] R.K. Bordia, G.W. Scherer, On constrained sintering-I Constitutive model for a sintering body, Acta Metall. 36 (1988) 2393-2397.

[19] S.H. Lee, G.L. Messing, D.J. Green, Bending creep test to measure the viscosity of porous materials during sintering, J. Am. Ceram. Soc. 86 (2003) 877-882.

[20] A. Peterson, J. Agren, Constitutive behavior of WC-Co materials with different grain size sintered under load, Acta Mater. 52 (2004) 1847-1858.

[21] J.C. Lagarias, J.A. Reeds, M.H. Wright, P.E. Wright, Convergence properties of the Nelder-Mead simplex method in low dimensions, SIAM J. Optim. 9 (1) (1998) 112-147. 